\title{
Research on Evaluation of Coordination of Regional Innovation Capacity and Regional Innovation Efficiency of Anhui
}

\author{
Luo Xuan ${ }^{1}$, Zhou Gang $^{2}$, Xie Yuan ${ }^{3}$, He Xiao Qing ${ }^{4}$ \\ 1. Hefei University of Technology, Hefei, Anhui; \\ 2. Hefei University of Technology, Hefei, Anhui; \\ 3. Hefei University of Technology, Hefei, Anhui; \\ 4. Hefei University of Technology, Hefei, Anhui)
}

\begin{abstract}
The regional innovation system is a versatile, complex structure of large-scale system, whether its innovation ability and efficiency of the development of coordination is the key to determine how well the regional innovation system development. Therefore, further study of regional innovation capacity and regional innovation efficiency of coordination issues, for the effective integration of regional innovation resources, improving regional innovation capabilities are of great significance. With Anhui province as the object of empirical study, and selection of the materials, analyzing it's with using evaluation index system and coordination degree model. Finally, according to the analysis of the results and actual development make recommendations appropriate to enhance regional innovation capacity and regional innovation efficiency coordinated development.
\end{abstract}

KEYWORDS: Regional Innovation System; Regional Innovation Capability; Regional Innovation Efficiency; Factor Analysis Method; Coordination Model

\section{Introduction}

Currently, the relationship between regional innovation capability and regional innovation efficiency hasn't been defined clearly at home and abroad, and researches putting them together are even rarer. However, regional innovation capability and regional innovation efficiency are the two important aspects to evaluate regional innovation system evolution status. Coordination of both is a direct indicator of the level of regional innovation system development. They are indivisible and influence each other, and coordinated development of them will be conducive to regional innovation system optimization and stability. At the same time, based on the viewpoint of system science, each internal part of the system must be harmonious cooperation, or otherwise any weak part will affect the development level of the whole system. Therefore, in this study, from the perspective of regional innovation system, we make objective, comprehensive and scientific evaluation of coordination of regional innovation capacity and regional innovation efficiency, striving to offer a proposal and foundation for regional innovation capacity and regional innovation efficiency of uncoordinated development area at present.

\section{Theoretical Review}

Regional innovation capability is a very macro concept, combining technology and institutional innovation theory. Because it involves many complex factors, so there is still not a clear consensus about it now. 
USA scholars Everett Rett and Judi are the earliest scholars who studied the regional innovation ability. After them, some experts also began to research on regional innovation ability. Foss (1966) thought that Regional innovation capability is the key factor of regional sustainable competition, which would not be transferred, purchased and copied. Stern and foreman (2002) thought an important measure of regional innovation capacity is the product innovation potential.

Currently, there is still not scholar accurately defining he concept of regional innovation efficiency. In a word, regional innovation efficiency is a concept of the input-output angle. Which is also Bear Pete' extension from definition of "innovation" and the concept of efficiency, from the perspective of economics.

Coordinated development of regional innovation system mainly refers to the cooperation and complementary relationship between the state subsystem characterized by regional innovation capability and process subsystem characterized regional innovation efficiency. Because of such positive relationship, the system it presents coordinated structure and state, making regional innovation capacity and regional innovation efficiency jointly revolute into a good direction, so the two subsystem have good matching relationship in aspects of function, relevant capacity and development speed, and finally achieve virtuous cycle of regional innovation and coordinated development of regional innovation system.

\section{Empirical Study}

\section{A. Evaluation Index System}

In this study, we definite the elements of regional innovation capability as regional innovation resource input capability and regional economic transformation ability of innovation and technology, which are interconnected and influence each other, with broad coverage. Among them, regional innovation resource input capability is a potential capability, while regional economic transformation ability of innovation and technology is the effect of capability. The specific indicators are shown in table 1:

Table 1. Evaluation Index System Of Regional Innovation Capability

\begin{tabular}{|c|c|}
\hline Primary index & Secondary index \\
\hline \multirow{4}{*}{ regional innovation resource input capability } & number of S \& T personnel $\mathrm{X}_{1}$ \\
\cline { 2 - 2 } & Full-time equivalent of R\&D personnel $\mathrm{X}_{2}$ \\
\cline { 2 - 2 } & R\&D Internal Expenditures $\mathrm{X}_{3}$ \\
\cline { 2 - 2 } & Proportion of R\&D Expenditures in GDP (\%) $\mathrm{X}_{4}$ \\
\hline \multirow{4}{*}{$\begin{array}{c}\text { regional economic transformation ability of } \\
\text { innovation and technology }\end{array}$} & Major scientific and technological achievements $\mathrm{X}_{5}$ \\
\cline { 2 - 2 } & Patent application granted $\mathrm{X}_{6}$ \\
\cline { 2 - 2 } & Technology market traded contract amount $\mathrm{X}_{7}$ \\
\cline { 2 - 2 } & GDP per capita $\mathrm{X}_{8}$ \\
\cline { 2 - 2 } & GDP growth rate $(\%) \mathrm{X}_{9}$ \\
\cline { 2 - 2 } & The industrial added value $\mathrm{X}_{10}$ \\
\cline { 2 - 2 } & High-tech industry output $\mathrm{X}_{11}$ \\
\cline { 2 - 2 } & \\
\cline { 2 - 2 } & \\
\cline { 2 - 2 } &
\end{tabular}


The premise condition of regional innovation behavior is combination way of innovative elements undergo new changes. The realization of regional innovation efficiency is to compare the status and effect of before and after the change, and is also the efficiency in the stage from input to output of innovation resources. According to the introduction of elements of regional innovation efficiency above, we can see that regional innovation efficiency consists of regional innovation resources input, regional innovation technology achievements output and regional innovation economic output, as shown in Figure 1:
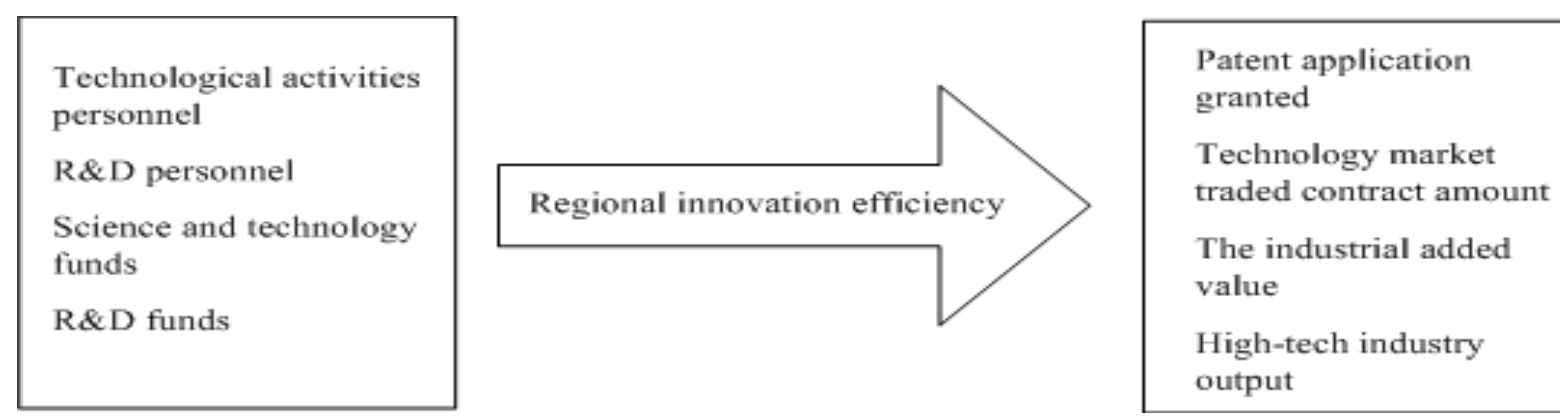

Figure 1. Regional Innovation Efficiency Index Selection

\section{B. Evaluation Model and Method}

(1) In order to eliminate the influence of dimensions and magnitude on calculation, firstly we need to conduct dimensionless of the original

$$
X_{i j}^{\prime}=\frac{X_{i j}-\min _{j} X_{i j}}{\max _{j} X_{i j}-\min _{j} X_{i j}}, \quad(i=1,2, \ldots \ldots, m, j=1,2, \ldots \ldots, n)
$$

In formula, $X_{i j}$ is original value of number $\mathrm{i}$ index in year $\mathrm{j} ; \min _{j} X_{i j}$ is the minimum value of number $\mathrm{j}$ index of all years; $\max _{j} X_{i j}$ is the maximum value of number $j$ index of all years.

(2) Determination of index weight. We adopt differential coefficient method to determine the weight of each index, shown as follow:

$$
\begin{aligned}
& \bar{x}_{j}=\frac{1}{n} \sum_{j}^{13} x_{i j}, \quad(j=1,2, \ldots . ., n) \\
& S_{j}=\sqrt{\frac{1}{n-1} \sum_{1}^{13}\left(x_{i j}-\bar{x}\right)^{2}}, \quad(j=1,2, \ldots \ldots, n)
\end{aligned}
$$

data of each index. Here we adopt the range transformation method, of which specific formula is as follow: 
(3) Measure of coordinated development value. In this study, we have simplified the regional innovation capability to the "sum" of innovation input capacity and output capacity, which is a synthesis of the "scale" or "volume"; while the regional innovation efficiency is regarded as a reflection of "structure" or "quality", that is, "ratio" of innovation output and innovation input.

1) Measure of development level of regional innovation capability (state subsystem)

According to the weight of the 11 evaluation index, we calculate the weighted sum of all the index value of Anhui in 2013, through Formula (6) as follow, and obtain the development level of Anhui province regional innovation system status subsystem $\mathrm{S}_{1}$ (regional innovation capability).

$$
L\left(S_{1}\right)=\sum_{i=1}^{11} \omega_{i} X_{i j}
$$

2) Measure of development level of regional innovation efficiency (process subsystem)

Measure of regional innovation efficiency is actually to calculate the ratio of innovation output and innovation resources input. We adopt the model formula as follow to determine the development level of Anhui province regional innovation system process subsystem $\mathrm{S}_{2}$ (regional innovation efficiency).

$$
L\left(S_{2}\right)=\sum_{i=5}^{11} \omega_{i} X_{i j} / \sum_{i=1}^{4} \omega_{i} X_{i j}
$$

Measure and evaluation of the development level and coordination evolution level of Anhui regional innovation capacity and innovation efficiency is to evaluate the coordinated development degree of its status subsystem $S_{1}$ and process subsystem $S_{2}$. In order to maintain consistency of data processing, we do dimensionless processing of $\mathrm{L}\left(\mathrm{S}_{1}\right)$ and $\mathrm{L}\left(\mathrm{S}_{2}\right)$ with Formula (1), which has no effect on development level of analysis subsystem. After dimensionless processing, suppose the development level of subsystem is $L^{\prime}\left(S_{1}\right)$ and $L^{\prime}\left(S_{2}\right)$.

3) Measure of comprehensive development level of Anhui regional innovation system

Regional innovation capability affects the development level of regional innovation system mainly from the perspective of innovative "quantity scale"; while regional innovation efficiency plays its role in development of regional innovation system from the perspective of "quality improvement". At some point, analysis of evolution state of regional innovation system involves the development level of these two aspects. Therefore, comprehensive development level of Anhui regional innovation system can be calculated by Formula (8) as follow:

$$
L(S)=\left[L^{\prime}\left(S_{1}\right)+L^{\prime}\left(S_{2}\right)\right] / 2
$$

4) Measure of coordination value of Anhui regional innovation capability and innovation efficiency

Coordination value can measure and describe the coordination state between the subsystems of the regional innovation system. The coordination value of Anhui regional innovation system innovation capability (state subsystem) and innovation efficiency (process subsystem) can be measured by relative deviation $\mathrm{VC}$ of $L^{\prime}\left(S_{1}\right)$ and $L^{\prime}\left(S_{2}\right)$. The calculation method of relative deviation $\mathrm{VC}$ is shown as Formula (9). The smaller is the value of $\mathrm{VC}$, the better coordination of system will be; conversely, the worse its coordination will be. 


$$
V C=\frac{\left|L^{\prime}\left(S_{1}\right)-L^{\prime}\left(S_{2}\right)\right|}{1 / 2\left[L^{\prime}\left(S_{1}\right)+L^{\prime}\left(S_{2}\right)\right]}=2 \sqrt{1-\frac{L^{\prime}\left(S_{1}\right) L^{\prime}\left(S_{2}\right)}{\left[\frac{L^{\prime}\left(S_{1}\right)+L^{\prime}\left(S_{2}\right)}{2}\right]^{2}}}
$$

Since $L^{\prime}\left(S_{1}\right)>0, L^{\prime}\left(S_{2}\right)>0$, the necessary and sufficient condition of the conclusion above is : the formula $\frac{L^{\prime}\left(S_{1}\right) L^{\prime}\left(S_{2}\right)}{\left[\frac{L^{\prime}\left(S_{1}\right)+L^{\prime}\left(S_{2}\right)}{2}\right]^{2}}$ reaches maximum. Based on this thinking, we define the coordination value of subsystem $S_{1}$ and $\mathrm{S}_{2}$ as:

$$
V C=\left\{\frac{L^{\prime}\left(S_{1}\right) L^{\prime}\left(S_{2}\right)}{\left[\frac{L^{\prime}\left(S_{1}\right)+L\left(S_{2}\right)}{2}\right]^{2}}\right\}^{k}
$$

\section{Data Processing}

(1) Data sources and processing

Apply the range transformation method above to calculate standardized data of each index, as shown in Table 2:

Table 2. Standardized Data Of Coordination Evaluation Index

\begin{tabular}{cccccc}
\hline Variables & $\mathrm{X}_{1}$ & $\mathrm{X}_{2}$ & $\mathrm{X}_{3}$ & $\mathrm{X}_{4}$ & $\mathrm{X}_{5}$ \\
\hline 2000 & 0.051913 & 0 & 0 & 0 & 0.222458 \\
2001 & 0.015483 & 0.013394 & 0.011621 & 0.275 & 0.163136 \\
2002 & 0.010929 & 0.030371 & 0.021684 & 0.191667 & 0 \\
2003 & 0.001821 & 0.056126 & 0.047371 & 0.25 & 0.063559 \\
2004 & 0 & 0.095841 & 0.066016 & 0.333333 & 0.184322 \\
2005 & 0.017304 & 0.141732 & 0.097738 & 0.3 & 0.29661 \\
2006 & 0.045993 & 0.200915 & 0.149079 & 0.383333 & 0.375 \\
2007 & 0.121129 & 0.280245 & 0.201698 & 0.475 & 0.487288 \\
2008 & 0.29326 & 0.359574 & 0.303561 & 0.533333 & 0.555085 \\
2009 & 0.675774 & 0.561157 & 0.452751 & 0.716667 & 0.75 \\
2010 & 0.687158 & 0.606431 & 0.548949 & 0.733333 & 0.792373 \\
2011 & 0.82969 & 0.777704 & 0.743476 & 0.8 & 0.961864 \\
2012 & 1 & 1 & 1 & 1 & 1 \\
\hline
\end{tabular}




\begin{tabular}{ccccccc}
\hline & $\mathrm{X}_{6}$ & $\mathrm{X}_{9}$ & $\mathrm{X}_{8}$ & $\mathrm{X}_{9}$ & $\mathrm{X}_{10}$ & $\mathrm{X}_{11}$ \\
\hline 2000 & 0.011018 & 0 & 0 & 0 & 0 & 0 \\
2001 & 0 & 0.003913 & 0.021609 & 0.047619 & 0.009862 & 0.009154 \\
2002 & 0.009349 & 0.017992 & 0.038621 & 0.095238 & 0.025822 & 0.019276 \\
2003 & 0.022705 & 0.033643 & 0.066374 & 0.142857 & 0.052686 & 0.038359 \\
2004 & 0.026377 & 0.037034 & 0.121254 & 0.666667 & 0.096157 & 0.055543 \\
2005 & 0.05576 & 0.101802 & 0.155904 & 0.555556 & 0.137423 & 0.086753 \\
2006 & 0.067112 & 0.154696 & 0.216844 & 0.968254 & 0.193971 & 0.157293 \\
2007 & 0.082137 & 0.254066 & 0.299979 & 0.888889 & 0.289236 & 0.216522 \\
2008 & 0.139566 & 0.32941 & 0.40046 & 0.698413 & 0.387311 & 0.28683 \\
2009 & 0.241736 & 0.368498 & 0.482382 & 0.730159 & 0.488737 & 0.357178 \\
2010 & 0.347245 & 0.499956 & 0.669634 & 1 & 0.673072 & 0.565882 \\
2011 & 0.652755 & 0.735748 & 0.869049 & 0.825397 & 0.882076 & 0.805098 \\
2012 & 1 & 1 & 1 & 0.603175 & 1 & 1 \\
\hline
\end{tabular}

(2) Apply differential coefficient method to determine the weight of each index, as shown in Table 3:

Table 3. Weight of Evaluation Index

\begin{tabular}{|c|c|c|c|c|c|c|c|c|c|c|c|}
\hline Index & $\mathrm{X}_{1}$ & $\mathrm{X}_{2}$ & $X_{3}$ & $\mathrm{X}_{4}$ & $\mathrm{X}_{5}$ & $\mathrm{X}_{6}$ & $\mathrm{X}_{7}$ & $\mathrm{X}_{8}$ & $\mathrm{X}_{9}$ & $\mathrm{X}_{10}$ & $\mathrm{X}_{11}$ \\
\hline $\begin{array}{c}\text { variation } \\
\text { Coefficient }\end{array}$ & 1.2820 & 1.0221 & 1.1326 & 0.6146 & 0.7506 & 1.4806 & 1.1502 & 0.9963 & 0.6503 & 1.0453 & 1.1739 \\
\hline $\begin{array}{l}\text { Weight } \\
\left(\omega_{i}\right)\end{array}$ & 0.113 & 0.090 & 0.1 & 0.054 & 0.066 & 0.131 & 0.102 & 0.088 & 0.058 & 0.093 & 0.104 \\
\hline
\end{tabular}

(3) Measure of coordinated development value According to the formula above, measure the coordination value of Anhui Regional innovation capability and innovation efficiency in 2013, as shown in Table 4: 
Table 4. Coordinated Development Value Of Anhui Regional Innovation System

\begin{tabular}{ccccc}
\hline Index & $\begin{array}{c}\text { Innovation } \\
\text { Capability }\end{array}$ & $\begin{array}{c}\text { Innovation } \\
\text { Efficiency }\end{array}$ & $\begin{array}{c}\text { Comprehensive } \\
\text { Development Level }\end{array}$ & $\begin{array}{c}\text { Coordination } \\
\text { Degree }\end{array}$ \\
\hline 2000 & 0.0221 & 2.7541 & 0.5000 & 0 \\
2001 & 0.0368 & 0.9295 & 0.0077 & 0.7915 \\
2002 & 0.0329 & 0.9848 & 0.0208 & 0.4230 \\
2003 & 0.0572 & 1.4200 & 0.1528 & 0.3719 \\
2004 & 0.1166 & 2.4896 & 0.4770 & 0.4415 \\
2005 & 0.1457 & 2.5629 & 0.5123 & 0.5802 \\
2006 & 0.2178 & 2.6794 & 0.5820 & 0.7794 \\
2007 & 0.2810 & 2.3002 & 0.5112 & 0.9694 \\
2008 & 0.3551 & 1.8352 & 0.4225 & 0.8650 \\
2009 & 0.4977 & 1.3498 & 0.3642 & 0.9635 \\
2010 & 0.6145 & 1.6980 & 0.5207 & 0.9379 \\
2011 & 0.7693 & 1.8183 & 0.6489 & 0.8458 \\
2012 & 0.9772 & 1.7252 & 0.7180 & \\
\hline
\end{tabular}

\section{Evaluation Results}

According to the values in Table 4, draw the capability and regional innovation efficiency, as shown in Figure 2: development trends graph of regional innovation

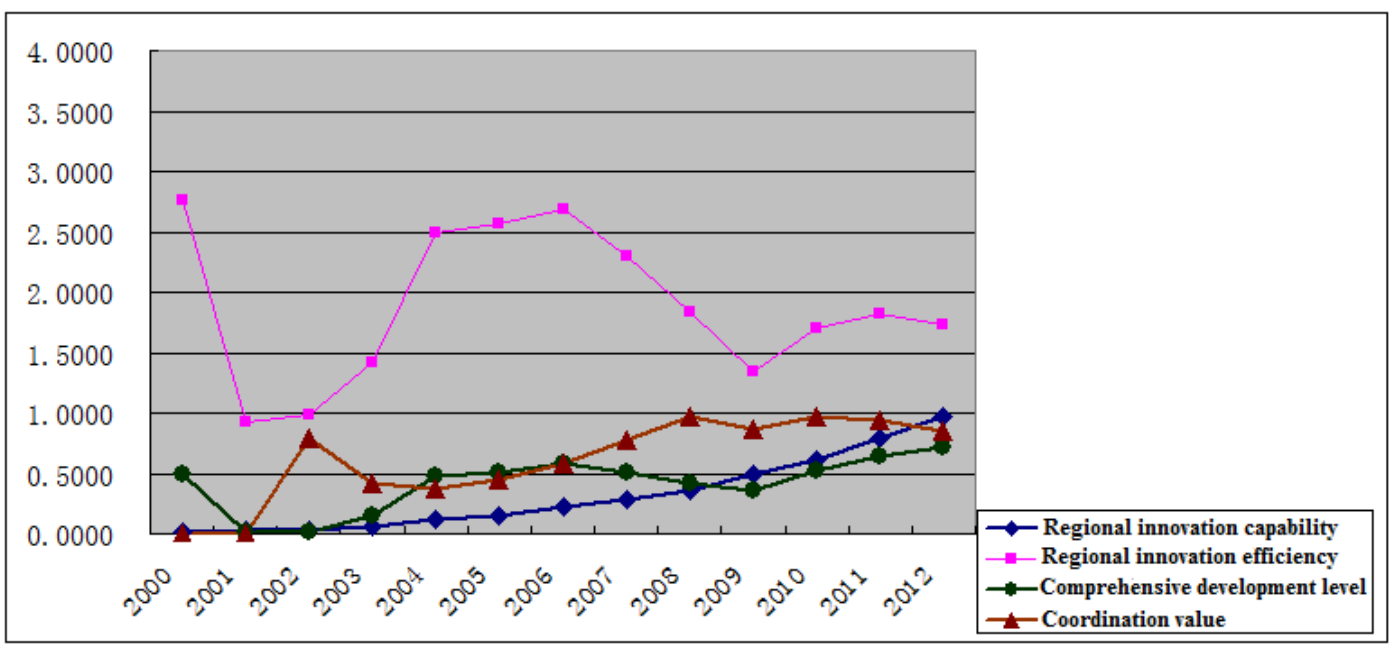

Figure 2. Development Trends Of Regional Innovation Capability And Regional Innovation Efficiency

Overall, the development level of Anhui regional innovation capability has been rising during 2000 2012, and reach the maximum in
2012. Meanwhile, during this period, coordination of Anhui regional innovation capability and regional innovation efficiency has 
experienced an evolution process from uncoordinated to progressive uncoordinated. From Figure 1, we can see that the construction of regional innovation capability doesn't match the development of regional innovation efficiency. However, since 2002, the construction of regional innovation ability has been strengthened, so Anhui regional innovation capability and innovation efficiency began to enter the coordinated state.

From the perspective of systematic comprehensive development level, Anhui development of regional innovation system is subject to the combined effect of regional innovation capability and regional innovation efficiency. Regional innovation system is a dynamic process of coordinated development, and the development level of the two subsystems together determines the overall evolution of the state of the system.

\section{CONCLUSIONS}

From the perspective of systematic coordinated development, it depends on development level of regional innovation capability and regional innovation efficiency and coordination relationship between them. Enhancing development level of a particular system is not conducive to enhance the overall development level of the system, but on the contrary, it may produce negative effects. Only when enhance synchronously can effectively promote the coordinated development of the whole system.

\section{REFERENCE:}

[1] Foss, N J. Knowledge-based approaches to the theory of the firm: some critical comments [J]. Organization Science, 1996, 7(5):470-476.

[2] Scott Stern, Michael E Porter, Jeffrey L Furman. The Determinants of National Innovative Capacity [J]. Research Policy, 2002, 31(6): 899-933.

[3] Riddel M, Schwer RK. Regional Innovative Capacity with Endogenous Employment: Empirical Evidence from the U.S. The Review of Regional Studies, 2003, 33(1).

[4] Xibao L. A Case Study on the Changes in the Innovation Capability of China's Regions: a Concept Based on the Innovation System [J]. Management World, 2007, 12: 18-30.

[5] Doloreux D, Parto S. Regional innovation systems: a critical synthesis[J]. Institute for New Technologies, United Nations University, 2004..

[6] Isaksen A, Trippl M. Regional industrial path development in different regional innovation systems: A conceptual analysis[R]. Lund University, CIRCLE-Center for Innovation, Research and Competences in the Learning Economy, 2014. 